\title{
Comparison of residual stress distributions in conventional and stationary shoulder high-strength aluminum alloy friction stir welds
}

DOI:

10.1016/j.jmatprotec.2016.11.015

\section{Document Version}

Accepted author manuscript

Link to publication record in Manchester Research Explorer

Citation for published version (APA):

Sun, T., Roy, M., Strong, D., Withers, P., \& Prangnell, P. (2017). Comparison of residual stress distributions in conventional and stationary shoulder high-strength aluminum alloy friction stir welds. Journal of Materials Processing Technology, 242, 92-100. https://doi.org/10.1016/j.jmatprotec.2016.11.015

Published in:

Journal of Materials Processing Technology

\section{Citing this paper}

Please note that where the full-text provided on Manchester Research Explorer is the Author Accepted Manuscript or Proof version this may differ from the final Published version. If citing, it is advised that you check and use the publisher's definitive version.

\section{General rights}

Copyright and moral rights for the publications made accessible in the Research Explorer are retained by the authors and/or other copyright owners and it is a condition of accessing publications that users recognise and abide by the legal requirements associated with these rights.

\section{Takedown policy}

If you believe that this document breaches copyright please refer to the University of Manchester's Takedown Procedures [http://man.ac.uk/04Y6Bo] or contact uml.scholarlycommunications@manchester.ac.uk providing relevant details, so we can investigate your claim.

\section{OPEN ACCESS}




\section{Accepted Manuscript}

Title: Comparison of Residual Stress Distributions in Conventional and Stationary Shoulder High-Strength Aluminum Alloy Friction Stir Welds

Author: Tianzhu Sun M.J. Roy David Strong Philip J. Withers

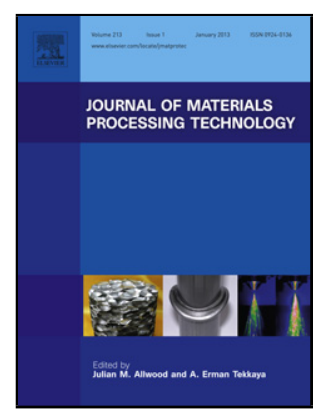
Philip B. Prangnell

PII:

DOI:

Reference: S0924-0136(16)30396-X

To appear in: Journal of Materials Processing Technology

Received date: $\quad 18-8-2016$

Revised date: $\quad 11-11-2016$

Accepted date: $\quad 12-11-2016$

Please cite this article as: Sun, Tianzhu, Roy, M.J., Strong, David, Withers, Philip J., Prangnell, Philip B., Comparison of Residual Stress Distributions in Conventional and Stationary Shoulder High-Strength Aluminum Alloy Friction Stir Welds.Journal of Materials Processing Technology http://dx.doi.org/10.1016/j.jmatprotec.2016.11.015

This is a PDF file of an unedited manuscript that has been accepted for publication. As a service to our customers we are providing this early version of the manuscript. The manuscript will undergo copyediting, typesetting, and review of the resulting proof before it is published in its final form. Please note that during the production process errors may be discovered which could affect the content, and all legal disclaimers that apply to the journal pertain. 


\title{
Comparison of Residual Stress Distributions in Conventional and Stationary Shoulder High-Strength Aluminum Alloy Friction Stir Welds
}

Tianzhu Sun ${ }^{\mathrm{a}}$, M. J. Roy ${ }^{\mathrm{b}}$, David Strong ${ }^{\mathrm{a}}$, Philip J. Withers ${ }^{\mathrm{a}}$ and Philip B. Prangnell ${ }^{\mathrm{a}}$

a School of Materials, the University of Manchester, Manchester M13 9PL, UK

b School of Mechanical, Aerospace and Civil Engineering, the University of Manchester, Manchester M13 9PL, UK

\begin{abstract}
The residual stresses generated in stationary shoulder friction stir welds (SSFSWs) produced in a typical high strength aluminum alloy (AA7010) in $6.3 \mathrm{~mm}$ thick plate have been mapped over full weld cross sections, using the contour method, and compared to those introduced by conventional friction stir welding (FSW) for welding speeds ranging from 100 to $400 \mathrm{~mm} / \mathrm{min}$. Compared to in conventional FSW, as a consequence of the material flow being affected by only a rotating probe, the SSFSW process produced a narrower and more uniform weld nugget and heat affected zone profile through the plate thickness. For both processes, 'M' shaped residual stress distributions were determined. However, the peak stresses measured in the SSFSWs were slightly lower than those found in the conventional FSWs and the width of the tensile region was appreciably reduced when using a stationary shoulder welding tool. This is shown to be a direct consequence of the more focused temperature distribution that results from using only a rotating probe to generate heat in the SSFSW process. In both processes, increasing the welding speed led to a narrower residual stress profile, but higher peak tensile residual stresses.
\end{abstract}

Keywords: Friction Stir Welding; FSW; Stationary Shoulder; Residual Stresses; Contour Method; Aluminum AA7010. 


\section{Introduction}

Friction stir welding (FSW) was invented by Wayne Thomas at the TWI in 1991 (Thomas, 1991). As discussed in a comprehensive reviews by Threadgill et al. (2009) and Mishra and Mahoney (2007), FSW has since attracted considerable interest for joining aluminum alloys, because it produces welds with excellent mechanical properties and avoids important detrimental issues normally found with fusion processes, such as solidification and liquation cracking. However research, for example by Long et al. (2007), has shown that the peak weld zone temperatures still reach close to the material's incipient melting point and as a result significant residual stresses and distortion can still be generated despite the solid-state nature of this welding process.

With the conventional FSW it is customary to employ a tool with a conjoined conical probe and a wider diameter shoulder that both rotate at the same rate. The function of the shoulder has been discussed by Threadgill et al., (2009) and is to constrain the plasticized material from escaping from the cavity produced by the pin as the tool translates. In the FSW community there is a general consensus (see for example work by Neto and Neto, 2013) that more heat is generated by the rotating shoulder than the probe, owing to its higher relative surface velocity, and this energy is conducted into the workpiece from the deformation zone under the shoulder, where the tool couples with the top surface of the plate. Because a significant downforce is normally employed on the tool, this accentuates the generation of heat at the top surface by the shoulder, which can be as high as $70-80 \%$ of the total welding power, although the ratio of power dissipation between the shoulder and probe depends on the probe length and contact conditions between the tool and work piece surface (Threadgill et al., 2009). As reported by Long et al. (2007) friction stir weld zones thus tend to be wider at the top surface of a joint and significant through-thickness temperature gradients have been observed by, for example Hassan et al. 
(2003), to cause associated microstructure and property gradients. Threadgill et al. (2009) have also reported that the use of a rotating shoulder constrains the weld geometries that can be joined and can generate flash as well as a poor surface finish.

More recently a variant of the conventional friction stir welding technique has been proposed by Russell (2008) that involves a tool design with a non-rotating shoulder. In this modification to the original welding method the shoulder contains a bearing housing through which the pin rotates, so that it remains 'stationary' relative to the pin and only slides across the workpiece surface as the tool is translated. As has subsequently been shown by Wu et al. (2015), with this tool configuration the sliding shoulder contributes little to heat generation and virtually all the welding energy is dissipated as plastic work from the interaction of the rotating pin with the workpiece. Davies et al. (2011) were one of the first groups to report employing a stationary shoulder tool for FSW. In their work the technique was applied to joining titanium alloys because their low conductivity makes it difficult to produce welds in thicker sections with the conventional FSW process without overheating the workpiece surface. They showed that when using stationary shoulder friction stir welding (SSFSW) to join Ti6Al4V a more homogeneous through-thickness microstructure could be obtained.

To date comparatively little has been published on SSFSW of aluminum alloys. However, Wu et al. (2015) and Avettand-Fènoël and Taillard (2016) have recently reported several advantages of applying the SSFSW technique to welding aluminum; including a narrower and more uniform through-thickness thermomechanical affected zone (TMAZ) and heat affected zone (HAZ), superior joint mechanical properties, and a much improved surface finish. Wu et al. (2015) has also shown that welds can be produced with lower power by SSFSW because it is more efficient to generate heat through-thickness with just the probe, than when it is also conducted into the 
weld from the near the top surface by the action of the shoulder. Because the diameter of the probe is much smaller than the shoulder, the work of Wu et al. (2015) has also found that with the tool dimensions they used a higher tool rotation rate was needed with the SSFSW process to generate sufficient heat to prevent probe failures. However, despite an overall difference in the welding power, the peak weld temperatures were found to be of a similar magnitude in both processes.

As has been discussed in the review by Withers (2007), large tensile residual stresses can be produced during welding processes which are of particular concern in aerospace applications because they can lead to premature fatigue failure. Authors, such as Richards et al. (2010) and Altenkirch et al. (2008), have investigated residual stresses in friction stir welds with highstrength aluminum alloys. They have typically found an ' $M$ ' shaped longitudinal stress distribution, where the peak tensile residual stresses are located near the HAZ and weld nugget zone (WNZ) boundary in the region below the edge of the shoulder and reach about $50 \%$ of the material's room temperature yield stress. The origin of this characteristic ' $M$ ' shaped residual stress profile has been attributed by Richards et al. (2008b) to the diffuse nature of the thermal field seen in FSW relative to other welding processes, combined with the high level of softening that occurs with high-strength aluminum alloys at elevated temperatures. In addition, both Lombard et al. (2009) and Peel et al. (2003) have found that in FSW the peak tensile residual stresses rise with increasing travel speed and this is the dominant welding parameter that determines the level of maximum residual stress. Finally, several methods have been found to be effective for reducing the residual stresses in FSW including the application of mechanical tensioning, or local cooling, by Richards et al. (2008a) and (2010) and post weld seam rolling by Huang et al. (2013). 
Although residual stresses are an important issue in FSW, particularly when aerospace applications are considered, currently the distribution arising from stationary shoulder welding has not been reported. Of particular interest, in this context, is whether the narrower weld zone and lower power input possible with the SSFSW process leads to a reduction in the peak tensile residual stresses. Before applying this new welding technique commercially it is also essential to understand how the welding parameters influence the residual stress distribution. To this end, in this paper the residual stresses generated by conventional FSW and SSFSW have been directly compared for both processes using welding tools with the same overall geometries, in welds produced with a typical high strength aluminum aerospace alloy (AA7010). The aim of this study was to explore the effect of the extreme bounds between welding in conventional FSW with the maximum possible shoulder heat inpu and when there is virtually no shoulder heat generation, with a stationary shoulder tool, on the respective residual stress distributions. A relatively high down force was thus employed to produce the FSW baseline welds which, as discussed by Upadhyay and Reynolds (2012), maximizes coupling between the workpiece and the shoulder. The welding conditions selected were based on a previous study by $\mathrm{Wu}$ et al. (2015), who adopted a systematic approach to finding equivalent welding parameters that could be used to directly compare the two methods. This was achieved by evaluating their torque rotation rate decay curves to find the region of minimum welding power for each process. The welds' macrostructures, hardness distributions, and thermal histories have also been characterized to assist in interpretation of the residual stresses developed in each process variant.

The residual stress measurements have been made using the contour method. This technique has recently been reviewed by Prime and DeWald (2013) and has certain advantages compared to diffraction based methods, such as synchrotron X-ray and neutron diffraction. For example, it is more cost-effective and there is no requirement to measure the ' $\mathrm{d}_{0}$ ' unstrained lattice parameter, 
which in aluminum aerospace alloys is strongly affected by variation in the local matrix solute content within the weld zone. As discussed by Prime et al. (2006) the contour method also allows 2D residual stress maps to be determined across full weld cross-sections, which is particularly useful when evaluating the effect of a stationary shoulder on the residual stress distribution in FSWs.

\section{Experimental details}

\section{Welding Procedure}

The geometries of the FSW and SSFSW tools manufactured for the welding trials were as comparable as possible. Both tools are shown in Fig. 1 and had a shoulder diameter of $18 \mathrm{~mm}$ and a $5.9 \mathrm{~mm}$ long conical threaded tri-flat pin, with root and tip diameters of $6.2 \mathrm{~mm}$ and $4 \mathrm{~mm}$. However, as is standard practice (for example see Mishra and Mahoney, 2007) to reduce material loss the FSW tool had a slightly concave shoulder and the FSW welds were produced with a $2.5^{\circ}$ tilt. In contrast, no tilt was used with the SSFSW tool and the shoulder had a slightly convex surface to allow it to slide more easily across the plate. FSW welding was performed in position control with a plunge depth of $0.2 \mathrm{~mm}$ to ensure maximum coupling between the shoulder and material. This approach was used to minimize slip under the tool shoulder and thus produce welds under conditions which represent the largest possible shoulder heat generation, and maximum difference between the two processes. In contrast SSFSW was carried out with a constant downforce of $30 \mathrm{kN}$ and the tool did not sink appreciably into the colder plate surface (full details of the processing conditions can be found in Wu et al., 2015).

The alloy used in the experiments was a $6.3 \mathrm{~mm}$ thick hot rolled plate of AA7010-T7651 (nominal composition in table 1) which was machined into $126 \mathrm{~mm} \times 300 \mathrm{~mm}$ coupons. Welds 
were produced in a bead-on-plate configuration down the center line of each plate. The full matrix of welding conditions used in the trials is summarized in Table 2. The difference in rotation speeds between the rotating and stationary shoulder FSW was necessary to ensure that sufficient heat was generated with the stationary shoulder tool to avoid tool failure (see Wu et al., 2015). However, it is evident from Table 2 that the energies determined from torque measurements delivered to the weld were comparable between the two methods. For the baseline FSW welds only the travel speed was varied because, as pointed out by Lombard et al. (2009), this is known to be the most important parameter to influence the peak stresses. For SSFSW process the effect of varying the rotation rate was also investigated with a constant travel speed of $200 \mathrm{~mm} / \mathrm{min}$ (see Table 2).

\section{Temperature Measurement}

K-type thermocouples with a $0.5 \mathrm{~mm}$ diameter were used to measure local temperature cycles during welding. The thermocouples were inserted into tightly fitting holes drilled into the bottom surface of each plate. Their locations were 5, 10, 20 and $30 \mathrm{~mm}$ away from the weld center, at a depth of $3 \mathrm{~mm}$ below the plate top surface. Consequently, the first location was only $2 \mathrm{~mm}$ laterally distant from the pin surface.

\section{Characterization}

The size and shape of the weld zones and the microstructure of all the welds were characterized from transverse (TD-ND) cross sections by optical microscopy. Samples were prepared by metallographic polishing to a $0.25 \mu \mathrm{m}$ finish, followed by etching in Keller's reagent. The hardness distributions' of all the welds were also mapped with a distance between measurements of $0.5 \mathrm{~mm}$, using a Struers DuraScan 80 automated Vickers hardness tester and an applied load of $0.5 \mathrm{~kg}$. 


\section{Contour Method of Residual Stress Measurement}

The procedure employed to measure residual stresses in the welds, using the contour method, first involved securing the plates to prevent any movement when cutting across the center of each weld, orthogonal to the welding direction. This was carried out with a wire electrodischarge machine (EDM) using a $250 \mu \mathrm{m}$ diameter brass wire in a low power skim-cutting mode. In this procedure the fixture employed during cutting is particularly critical as it needs to prevent movement during, while minimizing any plastic deformation. Self-restraint features, in the form of $3 \mathrm{~mm}$ diameter holes located $3 \mathrm{~mm}$ from the free edges of the plate, in conjunction with a heavy fixture were used to prevent each side of the cut moving - as shown in see Fig. 2. The two cut faces produced by sectioning each plate were subsequently scanned with a Nanofocus $\mu$ Scan laser profilometer using a CF-4 sensor, producing a point cloud with a spacing of 30 by $30 \mu \mathrm{m}$ and an out-of-plane height resolution of $0.2 \mu \mathrm{m}$.

The two datasets were then registered and averaged to form a single point cloud to eliminate effects due to shear and asymmetry, as recommended by Prime and DeWald (2013). The averaged point cloud surface was then fitted with a bivariate cubic spline with a knot spacing of $0.4 \mathrm{~mm}$. This spline was then used to elastically distort the flat cut face of a linear elastic finite element model, developed in ABAQUS ${ }^{\mathrm{TM}}$, comprising approximately 93600 quadratic (C3D20R) elements, as shown in Fig. 3. In this analysis the elastic properties of AA7010 were taken to be; Young's modulus, E, $=71.7 \mathrm{GPa}$ and Poisson's ratio, $v=0.33$. Self-restraint features were not included in the analysis, a simplification which has previously been shown to still provide accurate results by Hosseinzadeh et al. (2016). More details of the best practice in employing the contour method can be found in a recent review by Hosseinzadeh et al. (2014). 


\section{Results and Discussion}

\section{Power Input and Weld Thermal histories}

In FSW the effective heat input is related to the power dissipated in the workpiece by the tool. As exemplified by Cui et al. (2010), the power can be determined from the torque recorded by the welding machine. Although mechanical losses occur in the machine and some heat flows into the welding head, the efficiency is quite high (typically around $80 \%$ reported by Neto and Neto, 2013), thus the measured torque gives a reasonable estimate of the effect of the welding conditions on the relative power input. The average spindle power measured at steady state is summarized for each weld in table 2 , where it can be seen that the gross power increases with travel speed for both processes, whereas the line energy derived from the torque measurements (heat input per unit weld length), decreases at higher welding speeds.

Examples of typical thermal histories measured during FSW and SSFSW are provided in Fig 4(a) from the closest thermocouple position (2 $\mathrm{mm}$ from the tool surface). The peak temperatures measured with distance from the weld center at the mid-plate position are also summarized in Fig. 4(b). It can be seen in Fig. 4 that the peak temperatures were generally lower by around $60 \mathrm{~K}\left(60^{\circ} \mathrm{C}\right)$ for the SSFSW welds and at the position closest to the tool they did not change greatly with travel speed. In addition, in Fig. 4(a) it is noteworthy that at the same travel speed the temperature rose equally rapidly in the FSWs and SSFSWs as the welding tool approached the measurement location, but that the plate welded by FSW tended to cool more slowly when the tool had passed. Equally, the gradient in peak temperature with distance from a weld center was shallower for the FSW process, due to the larger power dissipated by this process and wider distribution of the heat input generated by the tool shoulder (Table 2). Finally, it can be seen that for both FSW and SSFSW steeper temperature gradients were recorded in the 
welds produced with higher welding speeds.

\section{Weld Macrostructures and Microhardness Distributions}

Macro view cross sections of the FSW and SSFSW samples produced with constant rotation rates and increasing travel speeds are displayed in Fig. 5. It can be seen that for both the FSW and SSFSW welds the cross sections show a nugget shape that is closely related to the tool profile. However, a more parallel through-thickness weld profile is seen for the SSFSWs because the TMAZ and HAZ at the weld crown is considerably narrower, due to the absence of a rotating shoulder. In both cases when a higher travel speed is used the TMAZ and HAZ become less wide, but this trend, caused by the lower line energy and contraction of the thermal field around the tool when the travel speed is increased, is more significant near the base of the conventional friction stir welds.

Micro-hardness maps are also shown in Fig. 6 from the TD-ND transverse weld cross sections, along with corresponding hardness profiles in Fig. 7across the mid-plate thickness of each weld. It should be noted that the hardness (and residual stress) measurements were made after the welds had naturally aged for 6-months. The parent material had an average hardness of 170175Hv. The slightly lower parent values seen at the center of the plates are probably caused by macro-segregation effects during DC casting. The hardness distributions for the conventional FSWs in Figs. 6 and 7 are comparable to those reported in several previous studies by, for example, Reynolds et al. (2005) and Peel et al. (2003). It can be seen in Fig. 6 that the HAZ is much wider near the top surface in the case of the FSW, compared to the SSFSW, and in Fig. 7 
for both processes the HAZ width and depth decreases with increasing travel speed.

In FSWs produced in alloys like AA7010 the weld zone hardness distribution is known to be mainly controlled by the state of matrix precipitation, although grain size refinement may also contribute to a small increase in the nugget yield stress. As has been discussed previously by several groups, including Malard et al. (2015), Sullivan and Robson (2008) and Su et al. (2003), there are two main mechanisms that determine the post-weld hardness distribution. Near the center of the welds where the peak temperature reached exceeded the solvus temperature (approximately $473{ }^{\circ} \mathrm{C}$ in AA7010, given in Hatch, 1984) full dissolution of the equilibrium and metastable strengthening phases can occur. As discussed by Kamp et al. (2006) this typically takes place in the weld nugget and can lead to strong post-weld natural ageing. Further out from the weld center, where the peak temperatures reached during welding were lower, the solvus temperature is not reached and a hardness drop normally occurs due to coarsening and/or dissolution of the fine metastable main strengthening phase $\eta^{\prime}$, which has been noted by Hassan et al. (2003) to be typically replaced by a coarser distribution of the stable equilibrium phase, $\eta$. The hardness minima in Fig. 7 are normally found located near the TMAZ/HAZ boundary, according to Threadgill et al. (2009) and Kamp et al. (2006), but the exact behavior depends on the specific thermal cycle. For example, in a similar alloy, Su et al. (2003) have reported that, although the precipitates at the HAZ minima position had coarsened (with more $\eta$ detected compared to in the parent material) some $\eta$ ' precipitates still survived. This suggests that at the HAZ minima positon the thermal cycle is not always sufficient for $\eta$ ' to fully dissolve, or transform, and coarsening of $\eta$ ' primarily determines the drop in hardness seen in the HAZ.

Overall, the hardness results in Fig. $6 \& 7$ confirm the observations of Wu et al. (2015) and Avettand-Fènoël and Taillard (2016) that in the SSFSWs, where the shoulder doesn't provide 
any significant heat input into the weld, a narrower and more uniform temperature distribution is generated through thickness. This in turn results in a narrower HAZ that varies less from top to bottom, owing to the HAZ width being particularly reduced at the weld top surface. However, it should be remembered that in the experiment here, which aimed to investigate the upper bound difference between the two welding approaches, the shoulder contact area was maximized by using a large plunge depth of $0.2 \mathrm{~mm}$. Although, as summarized in reviews by Mishra and Mahoney (2007) and Threadgill et al. (2009), it is generally stated that for conventional FSW welding about $70-80 \%$ of the total energy arises from the tool shoulder this is highly dependent on the probe length, which affects the probe to shoulder surface area ratio, and the degree of coupling between the shoulder and plate surface. The heat generated by the shoulder in particular depends strongly on the contact area, where sticking occurs, and the material flow stress, which are in turn dependent on the level of softening occurring at high temperature, as well as the downforce employed and tool design. For example, Colegrove et al. (2007) have shown that the contact area over which sticking occurs is typically considerably smaller than the shoulder area. The actual shoulder heat input is thus very dependent on the process conditions and, as has been demonstrated by Upadhyay and Reynolds (2012), can be significantly reduced if a lower down force is used, which will decrease the difference between the two processes. In summary, maximizing the level of shoulder heat generation is not an efficient way of delivering heat to the weld root and as discussed by Wu et al. (2015) this results in a higher overall welding power being required for FSW (by about 30\%) relative to the SSFSW case.

Finally, with both process variants increasing the travel speed can be seen to narrow the overall HAZ width and increased the hardness level seen at the minima positions (Fig. 7). A reduction HAZ width with increasing travel speed is typical in most welding processes. In FSW of heattreatable aluminum alloys this is caused by three main effects. Firstly, with a constant rotation 
rate the welding power does not rise sufficiently to compensate for an increase in travel speed so that the line energy, or heat input falls, as shown by Cui et al., (2010). Secondly, because there is less time for heat transfer, the thermal field becomes more elliptical and shrinks towards the tool surface. Thirdly, there is a reduction in the time at temperature, so that less over-aging occurs at a particular peak temperature. Due to kinetic considerations, as pointed out be Sullivan and Robson (2008), this has the effect of making the HAZ narrower because the minima position will tend to shift to a higher peak temperature in the thermal field.

\section{Comparison of the Residual Stress Distributions}

Although, as pointed out by Prime and DeWald (2013), it is difficult to use the contour method to measure other stress components apart from those parallel to the welding direction, in butt welding the longitudinal residual stresses have the largest magnitude and are thus generally of greatest interest. Maps of the longitudinal residual stress distributions determined over the weld cross-sections are shown in Fig. 8, where in both the SSFSWs and FSWs a peak in the tensile residual stresses can be seen located about the welds centers' and lower balancing compressive residual stresses are present outside of this tensile region. It is also readily apparent that the tensile region is always wider for the conventional FSWs compared to the SSFSWs and, in both sets of samples, the tensile longitudinal stress field reduces in width and increases in peak magnitude as the travel speed is increased.

As it is difficult by eye to compare the magnitudes of the residual stresses in contour plots, residual stress line profiles from the mid-plate thickness are provided in Fig. 9, for the FSW and SSFSW sample sets produced with different welding speeds. In general terms, the results for the FSW samples show good agreement with previously published measurements made by Peel et al. (2003), as well as Woo et al. (2011) and Sutton et al. (2002), who report similar magnitudes 
for the maximum residuals stress levels and comparable ' $\mathrm{M}$ ' shaped residual stress profiles. However, in Fig. 9 it is immediately apparent that the residual stress profiles seen for the two processes are different. The welds produced by the SSFSW are significantly narrower and have peak stresses are around the position of the edge of the pin. In comparison in the FSW samples a much wider longitudinal residual stress profile is observed. The peak stresses in this case are situated near the edge of the TMAZ in the region below the edge of the shoulder where there is a high heat input from the shoulder. It is also evident from Fig. 9 that the tensile region becomes narrower with the increasing travel speed and the peak stresses increase in magnitude for both processes. For both processes this results in greater overlap, or convergence, of the ' $\mathrm{M}$ ' shaped twin maximum stress peaks as the welding speed increases.

To better compare the effect of travel speed on the peak longitudinal residual stresses for both process these values are plotted in Fig. 10. In this graph it is notable that for the same welding speed the peak stresses are always slightly higher for the FSW process, but this difference reduces and become marginal at higher travel speeds where the results converge.

The development of the ' $M$ ' shaped residual stress distribution seen in the conventional FSW with high strength aluminum alloys and again here in SSFSW has previously been discussed in detail in the work of Richards et al. (2008a). In this paper a thermal FE model coupled with a microstructural softening model was used to show that the residual stresses generated can be largely explained purely in terms of the effect of the thermal field without considering the mechanical effect of the tool, because the zone of compressive plastic relaxation ahead of the tool is generally much larger than the region deformed by the tool. However, Li et al. (2007) have used a simplified coupled thermo-mechanical model to demonstrate that the forces from the welding tool may have a secondary mechanical effect on the residual stresses. This model has 
predicted that pressure from the tool will slightly reduce the magnitude of the residual stresses. Asymmetry in the tool reaction forces was also used to help explain the fact that the peak residual stresses are often slightly higher on the advancing side of the weld zone. For example, the FSW profiles in Fig. 9 at a high travel speed show a higher peak stress on the advancing side (AS) of the weld and a similar effect is seen in other data published in the literature, such as in the results of Altenkirch et al. (2008), although this has normally been correlated to asymmetry in the heat generation.

Following the argument of Richards et al. (2008a), in FSW of high strength aluminum alloys the residual stress distribution is determined by the interaction of the temperature dependent yield stress locus firstly with the compressive misfit ahead of the tool, as the temperature rises, and then behind the tool as the tensile misfit builds up on cooling and is partially relaxed by plastic deformation. In this context the softening behavior is very important because the material being welded has a very dramatic dependence of its flow stress with temperature and becomes very soft within the weld region. For example, values as low as10 MPa have been suggested by Colegrove et al., (2007). The importance of this behavior is shown in Fig. 11, adapted from Richards work. In FSW, because of the relatively diffuse thermal field, the zone of compressive elastic deformation ahead of the tool is relatively wide, and this is nearly full relaxed across a relatively large area where the material is at a high temperature and the flow stress is negligible (line 1 in Fig. 11). This region then develops a tensile misfit as it cools behind the tool when the tool advances. In the conventional process, because of the wider heat input from the shoulder, the material is still very soft across the center of the weld immediately behind the tool, giving a central region with a very low relatively uniform flow stress that readily relaxes and limits the buildup of residual stress (line 2 in Fig 11). However, further out, transverse to the welding direction, there is a steep gradient in temperature and, thus also yield stress, where residual 
stresses will develop more quickly. This behavior leads to a slightly higher stress at the edge of the weld zone and the ' $M$ ' shaped profile noted above. These stresses then become 'fixed' in at the point when the tensile residual stresses develop at a lower rate than the yield stress increases, as the temperature drops with distance behind the tool. The residual stress profile then separates from the tensile temperature dependent yield locus (see Fig. 10 line 3), so that no further relaxation occurs and the increasing misfit is thereafter accommodated elastically. The final residual stress distribution is therefore highly sensitive to the softening behavior of the material and the size of the compressive misfit created by the temperature field.

In the welds studied, the FSWs were produced with a high shoulder heat input and the large thermal field thus leads to a wider region where a tensile misfit develops behind the tool because the compressive region of plastic relaxation that develops as the tool approaches will also be larger. This ultimately also leads to a wider tensile region in the final weld, and for the reasons discussed above, a broad ' $M$ ' shaped residual stress profile, because of the wide region of nearly uniformly low flow stress that relaxes the tensile misfit near the weld center line. In contrast, with the SSFSW process, the thermal field is considerably narrower, leading to a smaller zone of compressive plastic relaxation and a narrower tensile residual stress region that develops behind the tool. The thermal gradient is also relatively steeper leading to shrinkage of the zone most softened by the heat generated by the tool. Consequently, both the yield stress locus and longitudinal residual stress distribution will be narrower and the two peaks seen in the conventional FSW ' $\mathrm{M}$ ' distribution will shrink so that a narrower, sharper, ' $\mathrm{M}$ ' shaped distribution is observed.

For similar reasons, it is also evident from Fig. 11 that as the thermal field shrinks with increasing welding speed the tensile region will also becomes narrower. This occurs because 
increasing the welding speed leads to a lower heat input (line energy, see table 2) as well as less time for thermal diffusion and the thermal field shrinks closer to the tool. As a result, the compressive misfit that results in the tensile residual stresses occurs over a smaller area and there is a corresponding reduction in the area of the tensile zone. In addition, the greater gradient in material flow stress that results from shrinkage of the thermal field reduces the amount of relaxation that occurs as the tensile zone develops behind the weld, increasing the peak residual stresses.

Finally, to see how significant the effect of rotation speed was on the residual stress measured in SSFSW, the residual stresses were measured in the welds made using a constant traverse speed of $200 \mathrm{~mm} / \mathrm{min}$ with increasing tool rotation rates (see Table 2). The residual stress distributions determined from these samples are shown in Fig. 12. Compared to the welds produced at different travel speeds (Fig. 9b), the change in the rotation speed appears to have had little effect on the residual stress. This behavior is in agreement with results previously reported by Lombard et al. (2009), who studied the residual stress in FSW under various welding speed and rotation rates. From their work Lombard et al. (2009) concluded that welding speed was the dominant factor affecting the peak tensile residual stresses, while rotation rate mainly only affected the width of the tensile region. In the experiments conducted here the welds were all produced within the viable process window developed by $\mathrm{Wu}$ et al. (2015), which gave a position on the torque decay curve with rotation rate where there was only a relatively small change in line energy on further increasing the rotation rate. As shown in Table 2, with the current probe dimensions, across the three rotation speeds the line energy only changed by $13 \%$, as compared to the line energy being more than halved by increasing the traverse speed, from 100 to 400 $\mathrm{mm} / \mathrm{min}$. This suggests that the power in these welds was limited by the material in the shear zone reaching a very low flow stress, where an increase in temperature may be compensating for an increase in strain rate with a higher shear rate (similar conclusions are reached in the work of 
Long et al. (2007) and Colegrove et al. (2007)). Unsurprisingly, this modest change in line energy therefore only gives rise to a relatively small increase in the thermal field size and change in the residual stress state.

\section{Conclusions}

The residual stress distributions in conventional FSW and SSFSW bead on plate, AA 7010T7651, welds have been directly compared using near-identical tool geometries. The welds were produced under conditions where coupling of the rotating shoulder with the conventional FSW process was maximized, so as to provide an upper bound difference between the two techniques.

It has been confirmed that a narrower weld hardness profile can be achieved with the SSFSW process, due to the lower power dissipation and more uniform though-thickness thermal field. This direct benefit from using a stationary shoulder results from a reduction in HAZ width at the weld crown, and more efficient heating of the material solely by the probe, rather than when a large proportion of the heat is conduction down in to the weld from the shoulder deformation zone.

The contour method gave results comparable to those published in the literature using alternative diffraction techniques and is thus demonstrated to be a suitable approach for $2 \mathrm{D}$ mapping the longitudinal residual stresses in FSW welds. An 'M'-shaped residual stress distribution was found in both processes. However, the tensile region in SSFSW was significantly narrower and the stationary shoulder process produced much sharper residual stress profiles. This difference is believed to be due to the considerably smaller thermal field developed with the stationary shoulder process, which reduces the size of the region of compressive misfit created by the local 
temperature rise ahead of the tool, and the width of the region of flow stress where plastic relaxation of the tensile misfit subsequently develops behind the tool. The peak residual stress values were also slightly higher in the conventional FSWs, but tended to converged between the two processes as the welding speed was increased.

The travel speed was found to be the more important in determining the maximum longitudinal residual stress, when compared to the rotation speed. This is partly because under the conditions studied the rotation rate did not as greatly affect the welding power. However, with a higher travel speed, there was a substantial reduction in the size of the thermal field, which led to a narrower tensile residual stress region in the welds. Increasing the travel speed also led to larger peak residual stresses, owing to the associated increase in the transverse yield stress gradient in the material with distance from the weld center.

Finally, it should be noted that by reducing the downforce associated with conventional FSW process it may be possible closer approach the case of SSFSW, by reducing the contact area over which a shoulder sticking condition occurs, but this has yet to be confirmed by accurate residual stress measurements.

\section{Acknowledgements}

We are grateful for financial support provided by EPSRC through LATEST2, (EP/G022402/1) and China Scholarship Council. We would also like to thank Mr. Ian Winstanley for performing the contour cuts. 


\section{References}

Altenkirch, J., Steuwer, A., Peel, M., Richards, D., Withers, P., 2008. The effect of tensioning and sectioning on residual stresses in aluminium AA7749 friction stir welds. Mater. Sci. Eng. A 488, $16-24$.

Avettand-Fènoël, M.-N., Taillard, R., 2016. Effect of a pre or postweld heat treatment on microstructure and mechanical properties of an AA2050 weld obtained by SSFSW. Mater. Design. 89, 348-361.

Carlone, P., Palazzo, G.S., 2013. Longitudinal residual stress analysis in AA2024-T3 friction stir welding. The Open Mech. Eng. J 7, 18-26.

Colegrove, P.A., Shercliff, H.R., Zettler, R., 2007. Model for predicting heat generation and temperature in friction stir welding from the material properties. Sci. Techol. Weld. Joining. 12, 284-297.

Cui, S., Chen, Z., Robson, J., 2010. A model relating tool torque and its associated power and specific energy to rotation and forward speeds during friction stir welding/processing. Int. J. Machine Tools Manu. 50, 1023-1030.

Davies, P., Wynne, B., Rainforth, W., Thomas, M., Threadgill, P., 2011. Development of microstructure and crystallographic texture during stationary shoulder friction stir welding of Ti-6Al-4V. Metal. Mater. Trans. A 42, 2278-2289.

Hassan, Kh. A. A., Prangnell, P. B., Norman, A. F., Price, D. A., and Williams, S.W., 2003, The Effect of Welding Parameters on the Nugget Zone Microstructure and Properties in High Strength AlAlloy Friction Stir Welds, Sci. Tech. Weld. Joining. 8, 257-268.

Hatch, J.E., 1984. Aluminum: Properties and Physical Metallurgy. publ. ASM International.

Hosseinzadeh, F., Kowal, J., Bouchard, P.J., 2014. Towards good practice guidelines for the contour method of residual stress measurement. J of Eng. 1-16.

Hosseinzadeh, F., Traore, Y., Bouchard, P., Muránsky, O., 2016. Mitigating cutting-induced plasticity in the contour method, part 1: Experimental. Int. J. Solids Structures. 94-95, 247-253. 
Huang, Y., Wan, L., Lv, S., Zhang, J., Fu, G., 2013. In situ rolling friction stir welding for joining AA2219. Mater Design. 50, 810-816.

Kamp, N., Sullivan, A., Tomasi, R., Robson, J., 2006. Modelling of heterogeneous precipitate distribution evolution during friction stir welding process. Acta Mater. 54, 2003-2014.

Li, T., Shi, Q., Li, H.-K., 2007. Residual stresses simulation for friction stir welded joint. Sci. Technol. Weld. Joining. 12, 664-670.

Lombard, H., Hattingh, D., Steuwer, A., James, M., 2009. Effect of process parameters on the residual stresses in AA5083-H321 friction stir welds. Mater. Sci. Eng. A 501, 119-124.

Long, T., Seidel, T.U., Tang, W., Reynolds, A.P., 2003. A friction stir welding model using computational fluid dynamics. In: 3rd Symposium on Hot Deformation of Aluminum Alloys, 2003 TMS Annual Meeting, San Diego, CA, USA, pp. 2-6.

Long, T., Tang, W., Reynolds, A.P., 2007. Process Response Parameter Relationships in Aluminum Alloy Friction Stir Welds. Sci. Technol. Weld. Joining. 12, 311-317.

Malard, B., De Geuser, F., Deschamps, A., 2015. Microstructure distribution in an AA2050 T34 friction stir weld and its evolution during post-welding heat treatment. Acta Mater. 101, 90-100.

Mishra, R.S., Mahoney, M.W., 2007. Friction stir welding and processing. ASM International.

Neto, D.M., Neto, P., 2013. Numerical modeling of friction stir welding process: A literature review. Int. J. Advanced Manu. Technol. 65, 115-126.

Paulo, R.M.F., Carlone, P., Valente, R.A.F., Teixeira-Dias, F. Palazzo, G.S., 2014. Influence of friction stir welding residual stresses on the compressive strength of aluminium alloy plates. Thin-Walled Struct. $74,184-190$.

Peel, M., Steuwer, A., Preuss, M., Withers, P., 2003. Microstructure, mechanical properties and residual stresses as a function of welding speed in aluminium AA5083 friction stir welds. Acta Mater. 51, $4791-4801$. 
Prime, M.B., DeWald, A.T., 2013. The contour method., In Practical Residual Stress Measurement Methods, Chapter 5, G. S. Schajer, (ed.), Wiley-Blackwell, 2013, pp. 109-138.

Prime, M.B., Gnäupel-Herold, T., Baumann, J.A., Lederich, R.J., Bowden, D.M., Sebring, R.J., 2006. Residual stress measurements in a thick, dissimilar aluminum alloy friction stir weld. Acta Mater. $54,4013-4021$.

Reynolds, A.P., Tang, W., Khandkar, Z., Khan, J.A., Lindner, K., 2005. Relationships between weld parameters, hardness distribution and temperature history in alloy 7050 friction stir welds. Sci. Technol. Weld. Joining. 10, 190-199.

Richards, D., Prangnell, P., Williams, S., Withers, P., 2008a. Global mechanical tensioning for the management of residual stresses in welds. Mater. Sci. Eng. A 489, 351-362.

Richards, D., Prangnell, P., Withers, P., Williams, S., Nagy, T., Morgan, S., 2008b. Simulation of the effectiveness of dynamic cooling for controlling residual stresses in friction stir welds. In: 7th Int. Symposium on Friction Stir Welding, Japan, TWI, UK.

Richards, D., Prangnell, P., Withers, P., Williams, S., Nagy, T., Morgan, S., 2010. Efficacy of active cooling for controlling residual stresses in friction stir welds. Sci. Technol. Weld. Joining. 15, 156165.

Russell, M., 2008. Recent developments in the stationary shoulder FSW of titanium alloys, 7th Int. Symposium on Friction Stir Welding, Japan, TWI, UK.

Su, J.-Q., Nelson, T., Mishra, R., Mahoney, M., 2003. Microstructural investigation of friction stir welded 7050-T651 aluminum. Acta Mater. 51, 713-729.

Sullivan, A., Robson, J., 2008. Microstructural properties of friction stir welded and post-weld heattreated 7449 aluminium alloy thick plate. Mater. Sci. Eng. A 478, 351-360.

Sutton, M., Reynolds, A., Wang, D.-Q., Hubbard, C., 2002. A study of residual stresses and microstructure in 2024-T3 aluminum friction stir butt welds. J. Eng. Mater. Technol. 124, 215-221. 
Thomas, W., 1991. Friction stir butt welding. Int. Patent Application No. PCT/GB92/0220.

Threadgill, P., Leonard, A., Shercliff, H., Withers, P., 2009. Friction stir welding of aluminium alloys. Int. Mater. Reviews. 54, 49-93.

Upadhyay, P., Reynolds, A.P., 2012. Effects of forge axis force and backing plate thermal diffusivity on FSW of AA6056. Mater. Sci. Eng. A 558, 394-402.

Withers, P., 2007. Residual stress and its role in failure. Rep. Prog. Phys. 70, 2211-2264.

Woo, W., Feng, Z., Wang, X.L., David, S.A., 2011. Neutron diffraction measurements of residual stresses in friction stir welding: a review. Sci. Technol. Weld. Joining. 16, 23-32.

Wu, H., Chen, Y.-C., Strong, D., Prangnell, P., 2015. Stationary shoulder FSW for joining high strength aluminum alloys. J Mater. Process. Technol. 221, 187-196. 
(a)

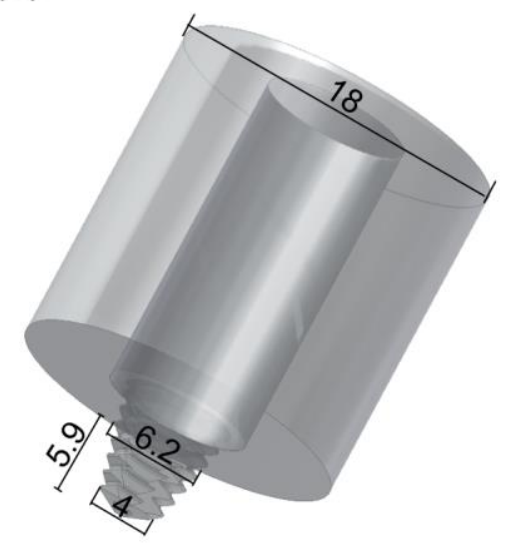

(b)

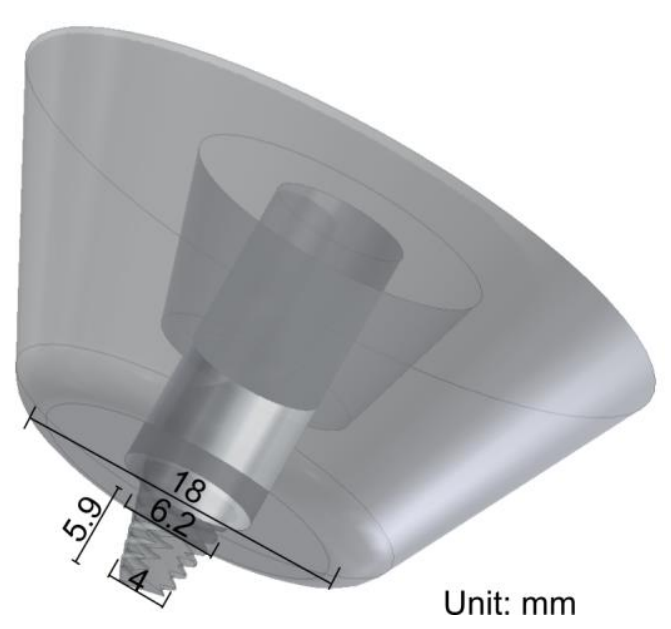

Fig.1: Schematic diagrams of (a) the FSW and (b) the SSFSW tools used in this study. 

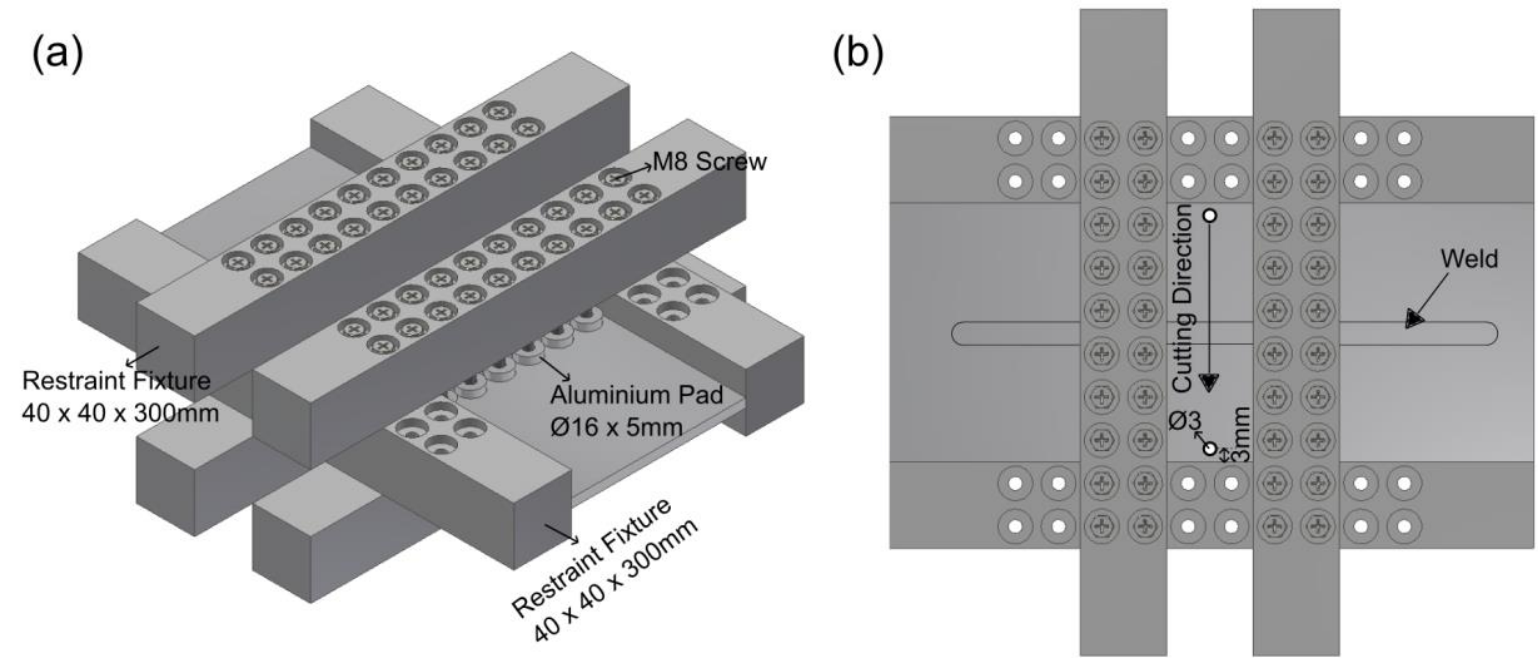

Fig. 2: Diagrams of the fixtures employed to EDM cut the welds when applying the contour method shown in (a) in an isometric and (b) plan views. 


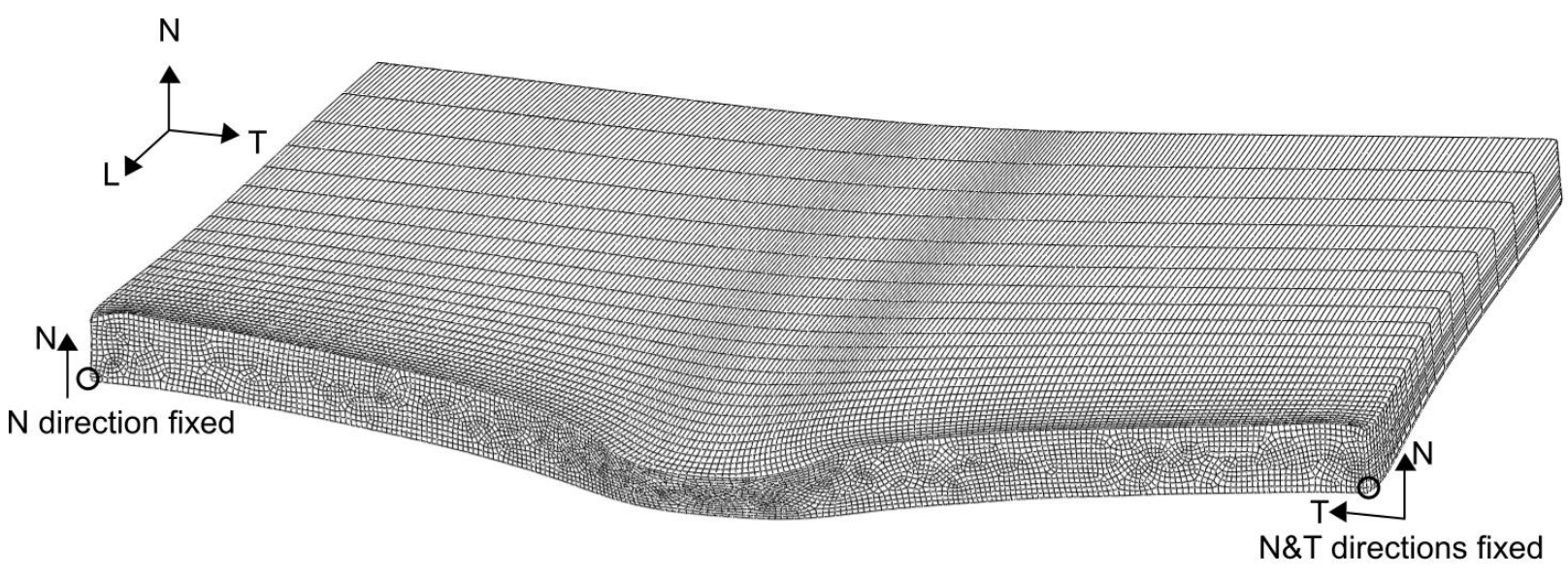

Fig. 3: An example of an elastic FE Model fitted to an EDM cut weld surface contour (displacement magnified by factor of 250) for an SSFSW weld produced with a rotation rate of $1500 \mathrm{rpm}$ and travel speed of $100 \mathrm{~mm} \mathrm{~min}^{-1}$. 

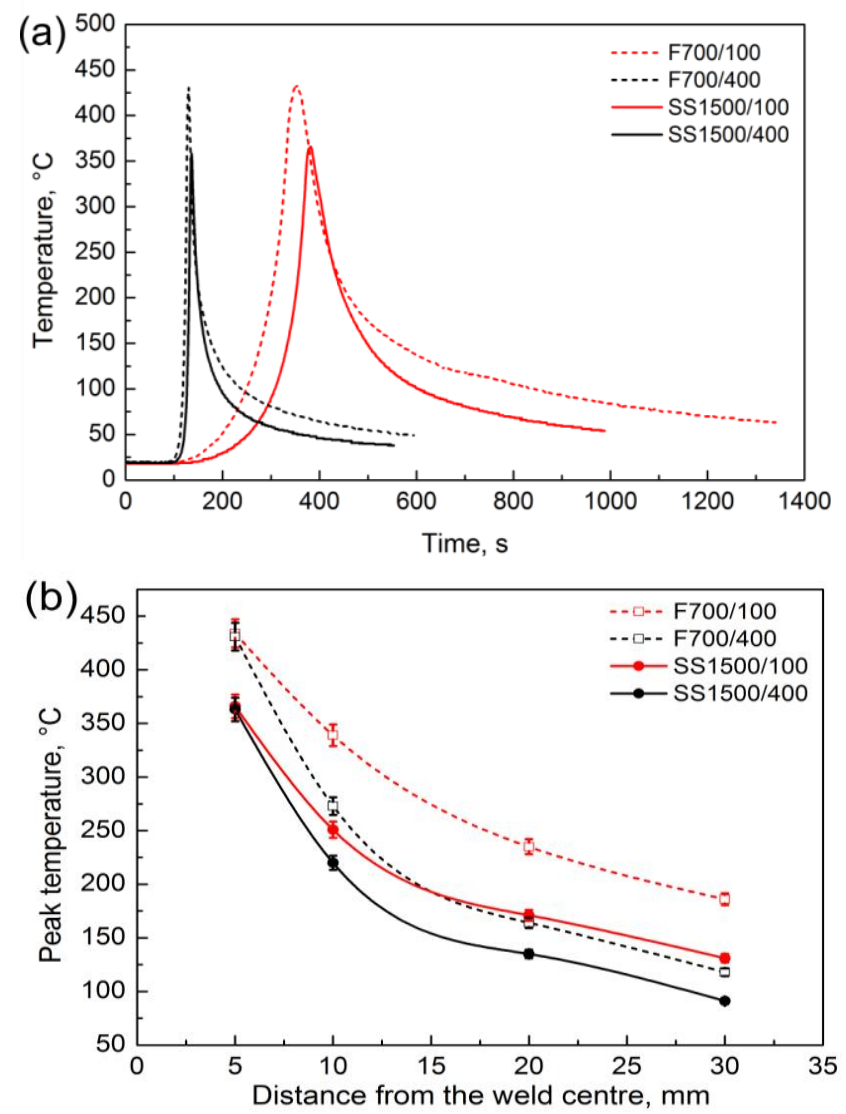

Fig. 4: Thermal data recorded from FSW and SSFSW welds, (a) temperature histories from the thermocouples positioned at the mid plane close to the pin $(2 \mathrm{~mm})$ and (b) a summary of the peak temperatures recorded as function of the distance from the weld centre, measured in welds produced with travel speeds of 100 and 400 $\mathrm{mm} / \mathrm{min}$ and $700 \mathrm{rpm}$ and $1500 \mathrm{rpm}$, for FSW and SSFSW, respectively (for the legend key see table 2). 
(a)

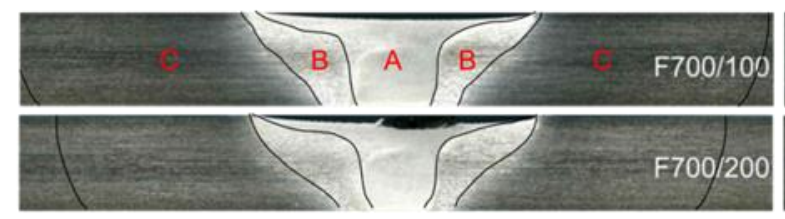

(b)

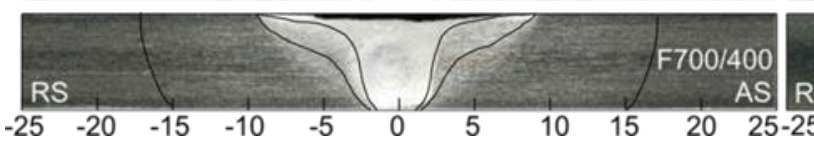

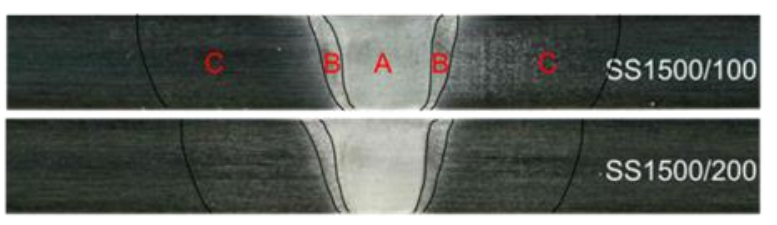

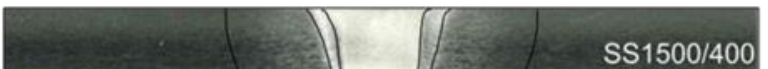

Fig. 5: Cross sections of the FSWs (a) and SSFSWs (b) produced with constant rotation rates of 700 and $1500 \mathrm{rpm}$, respectively, and increasing travel speeds (the labels indicate; A the weld nugget, B TMAZ and C the HAZ ). The retreating side (RS) is on the left the advancing side (AS) on the right. 
(a)

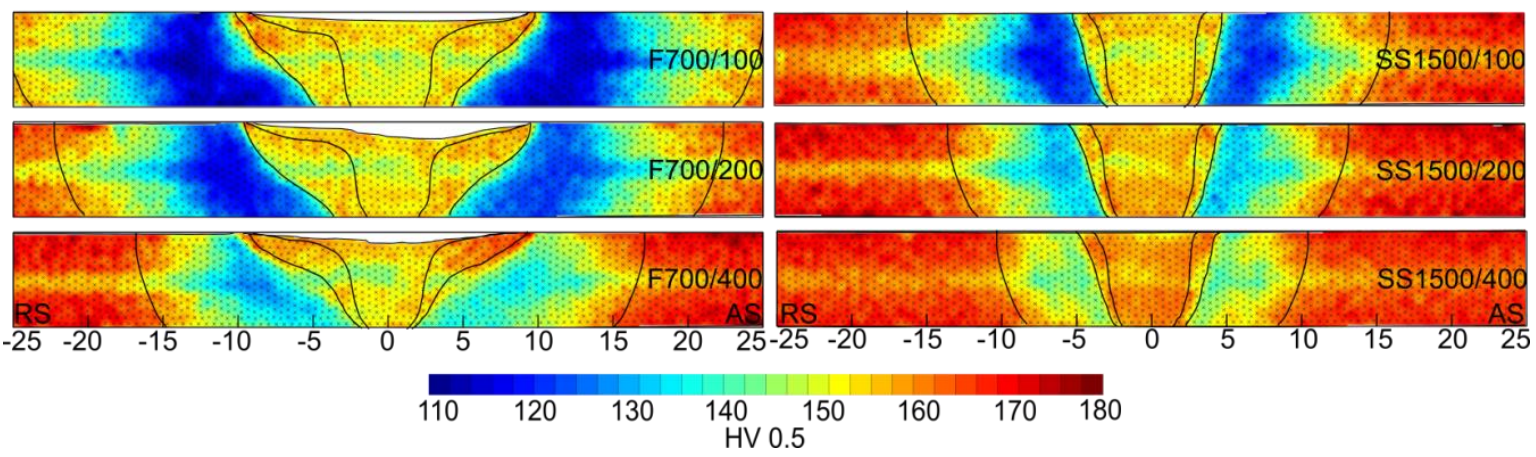

Fig. 6: Hardness maps from (a) FSW and (b) SSFSW cross sections, measured after six months post-weld natural ageing, produced with travel speeds of 100, 200, and $400 \mathrm{~mm} / \mathrm{min}$ and $700 \mathrm{rpm}$ and $15000 \mathrm{rpm}$ for FSW and SSFSW, respectively. The measurement grid used is indicated by the black dots. 

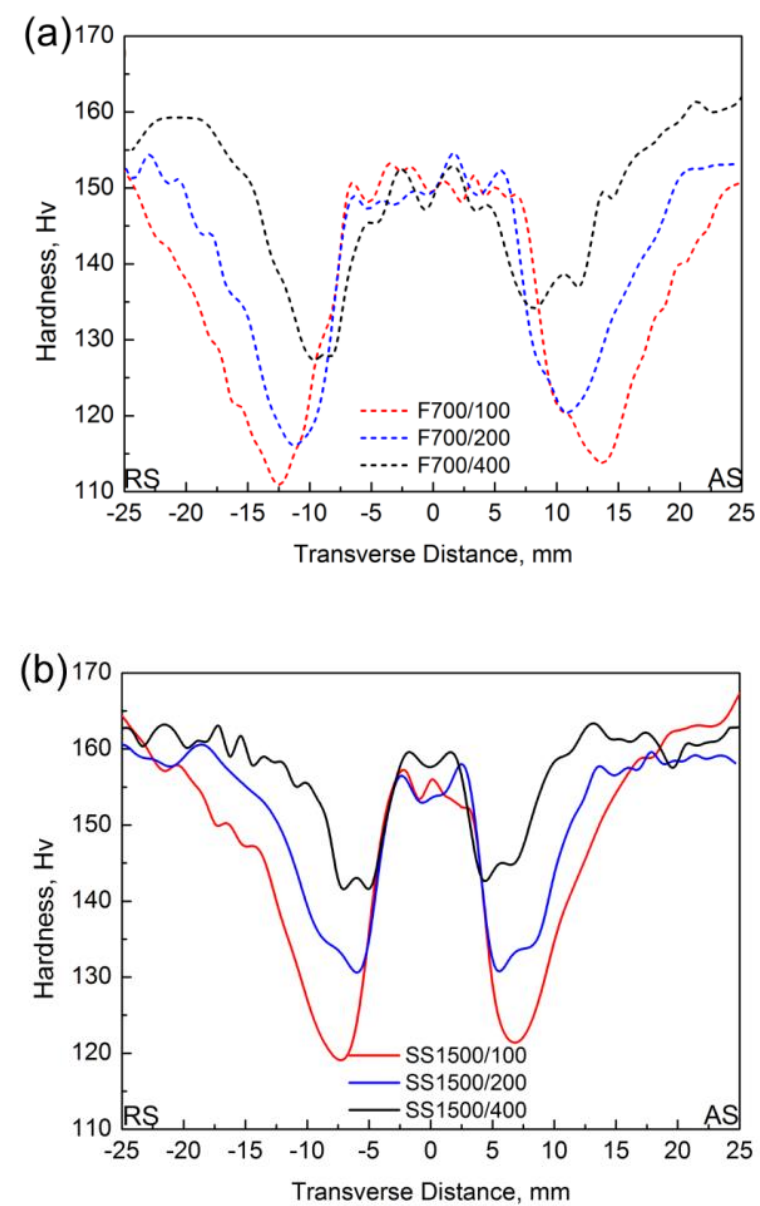

Fig. 7: Mid-thickness cross-weld hardness distributions for (a) FSW and (b) SSFSWs, measured after post-weld natural ageing for six months, with travel speeds of 100, 200, and $400 \mathrm{~mm} / \mathrm{min}$ and $700 \mathrm{rpm}$ and $15000 \mathrm{rpm}$ for FSW and SSFSW, respectively. 
(a)
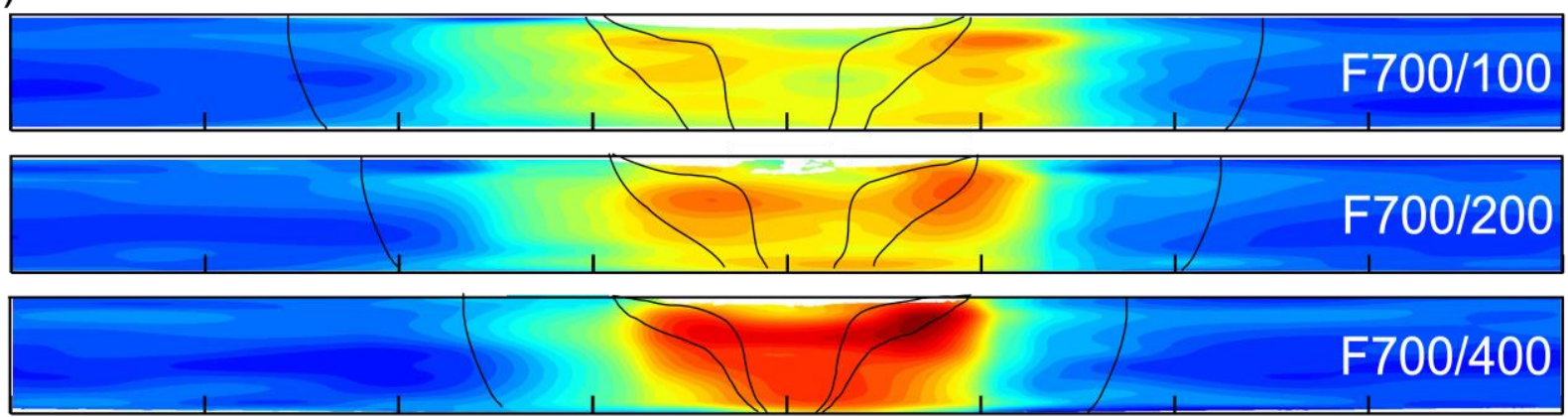

(b)
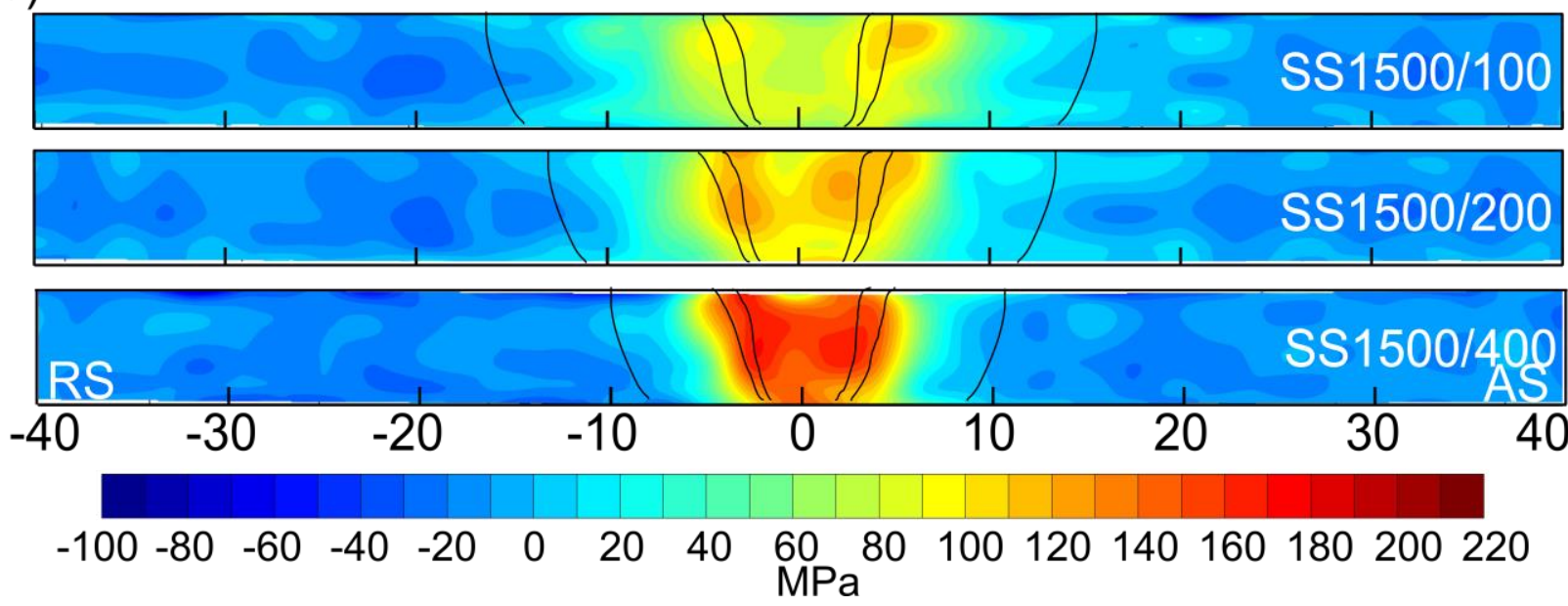

Fig. 8: Longitudinal residual stress maps measured for (a) the FSWs and (b) SSFSWs (the welding parameters are shown on each map). The black lines indicate the boarders of the weld zones identified in Fig. 5. 

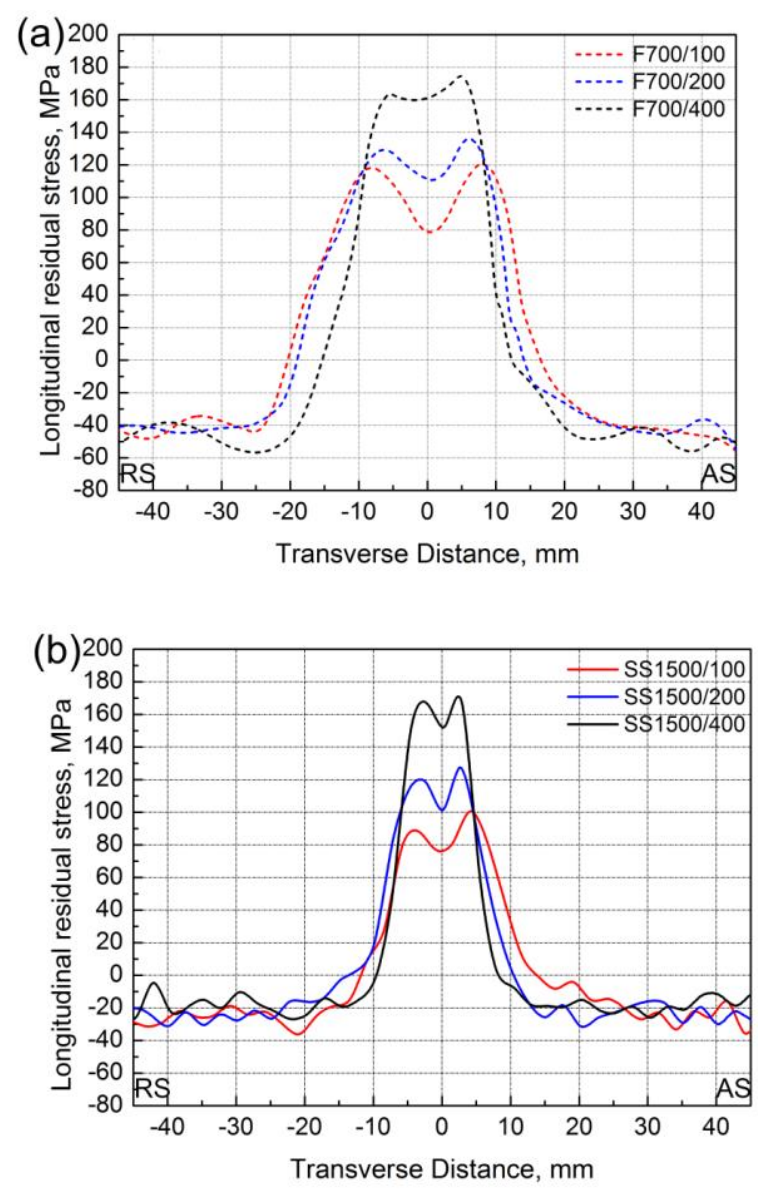

Fig. 9: Longitudinal residual stress distributions measured across the welds' mid-plane; for (a) the FSW and (b) the SSFSW samples, with increasing travel speed. 


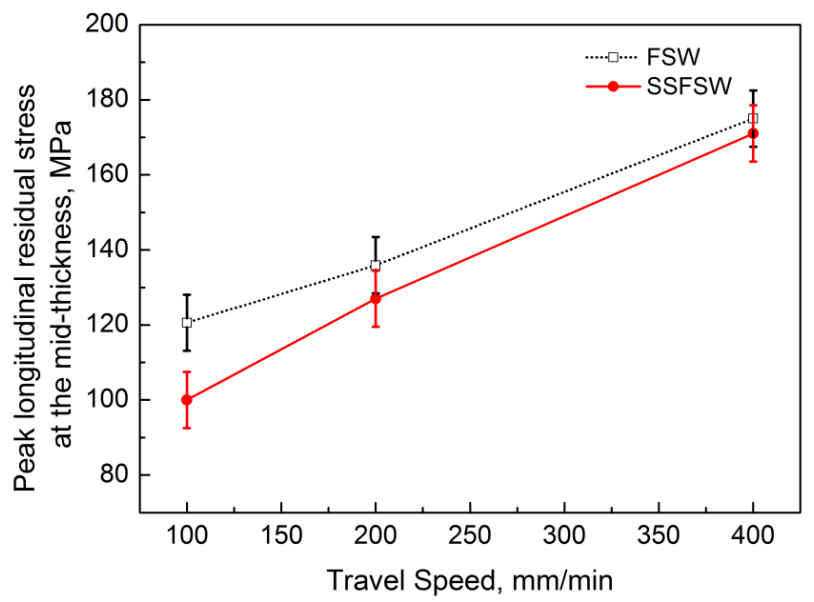

Fig. 10: Comparison of the peak longitudinal residual stresses measured at the welds' mid-plane, plotted as a function of travel speed, for the conventional FSW and stationary shoulder (SSFSW) processes. 

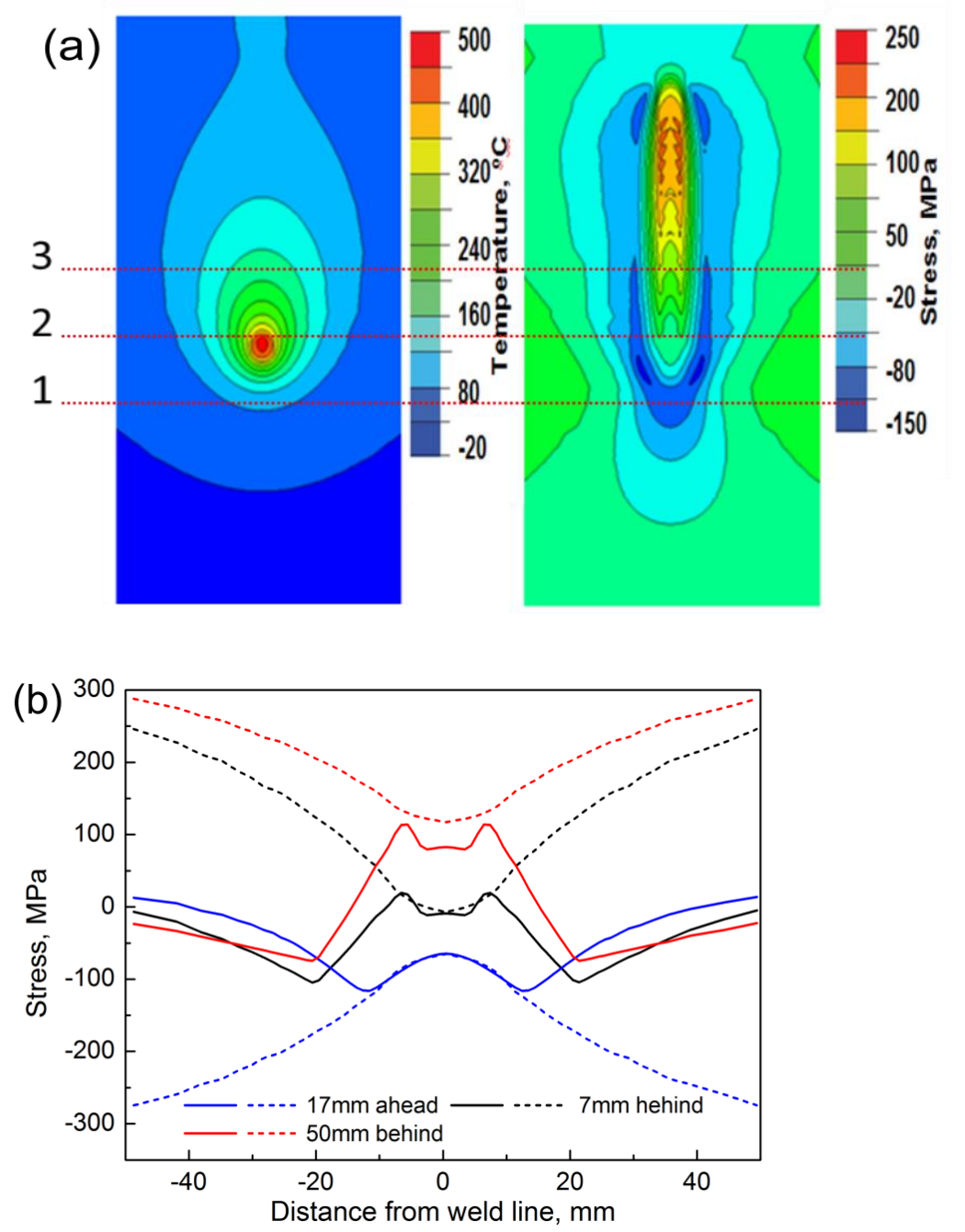

Fig. 11: The predicted development of longitudinal residual stresses across the mid-plane of a conventional FSW, adapted from the work of Richards et al., (2008a) showing; in (a) the $2 \mathrm{D}$ temperature distribution and corresponding longitudinal residual stress field and (b) the development of longitudinal residual stresses profiles (solid lines) at different distances from the tool (indicated in (a)) plotted along with the temperature dependent tensile and compressive yield loci (dashed lines). 


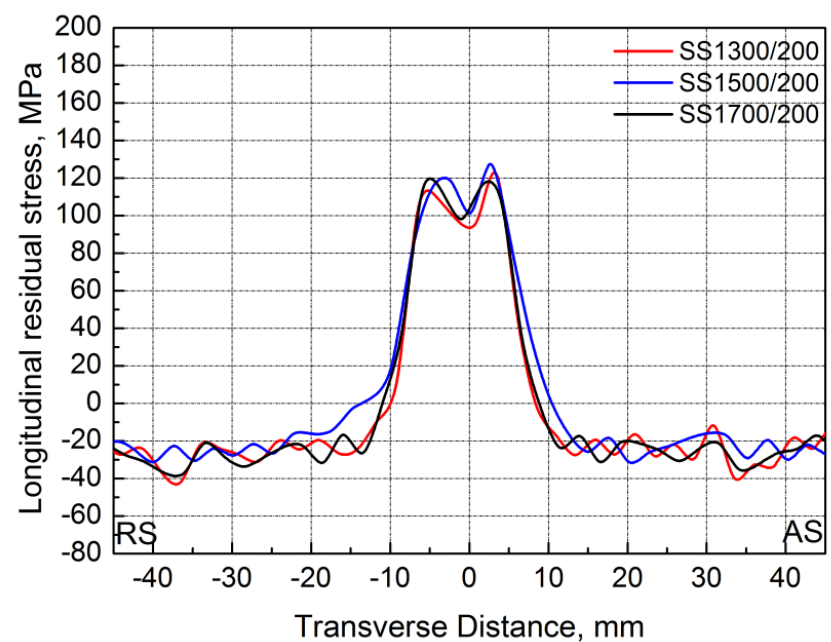

Fig. 12: Longitudinal residual stress distributions measured at the mid-thickness across SSFSWs with different rotation rates (1300-1700 rpm) and a constant travel speed of $200 \mathrm{~mm} / \mathrm{min}$. 
Table 1: Nominal compositions of Al 7010-T7651 alloy.

\begin{tabular}{lllllllllllllll}
\hline \multicolumn{1}{l}{ Chemical composition limits } & \multicolumn{1}{l}{ Others } \\
\hline Weight \% & $\mathrm{Al}$ & $\mathrm{Zr}$ & $\mathrm{Si}$ & $\mathrm{Fe}$ & $\mathrm{Cu}$ & $\mathrm{Mn}$ & $\mathrm{Mg}$ & $\mathrm{Cr}$ & $\mathrm{Zn}$ & $\mathrm{Ti}$ & Each & Total \\
Minimum & 87.3 & 0.08 & - & - & 2.0 & - & 1.9 & - & 5.7 & - & - & - \\
Maximum & 90.3 & 0.15 & 0.12 & 0.15 & 2.6 & 0.10 & 2.6 & 0.04 & 6.7 & 0.06 & 0.05 & 0.15 \\
\hline
\end{tabular}


Table 2: The matrix of conventional (FSW) and stationary shoulder (SSFSW) welding parameters used in this paper.

\begin{tabular}{llllll}
\hline Designation & $\begin{array}{l}\text { Welding } \\
\text { Technique }\end{array}$ & $\begin{array}{l}\text { Rotation speed } \\
(\mathrm{rpm})\end{array}$ & $\begin{array}{l}\text { Travel } \\
(\mathrm{mm} / \mathrm{min})\end{array}$ & $\begin{array}{l}\text { Speed } \\
\text { Power }(\mathrm{W})\end{array}$ & $\begin{array}{l}\text { Line } \\
\text { energy }(\mathrm{J} / \mathrm{mm})\end{array}$ \\
\hline F700/100 & FSW & 700 & 100 & 2210 & 1324 \\
F700/200 & FSW & 700 & 200 & 2880 & 863 \\
F700/400 & FSW & 700 & 400 & 3050 & 458 \\
SS1500/100 & SSFSW & 1500 & 100 & 1330 & 796 \\
SS1500/200 & SSFSW & 1500 & 200 & 1550 & 464 \\
SS1500/400 & SSFSW & 1500 & 400 & 2360 & 355 \\
SS1300/200 & SSFSW & 1300 & 200 & 1750 & 526 \\
SS1700/200 & SSFSW & 1700 & 200 & 1610 & 482 \\
\hline
\end{tabular}

